\title{
Applicability of DNA pools on 500 K SNP microarrays for cost-effective initial screens in genomewide association studies Sophia J Docherty* ${ }^{\dagger}$, Lee M Butcher ${ }^{\dagger}$, Leonard C Schalkwyk and Robert Plomin
}

Address: Social, Genetic and Developmental Psychiatry Centre, Box Number P082, Institute of Psychiatry, DeCrispigny Park, London, SE5 8AF, UK

Email: Sophia J Docherty* - sophia.docherty@iop.kcl.ac.uk; Lee M Butcher - lee.butcher@iop.kcl.ac.uk;

Leonard C Schalkwyk - l.schalkwyk@iop.kcl.ac.uk; Robert Plomin - r.plomin@iop.kcl.ac.uk

* Corresponding author †Equal contributors

Published: 4 July 2007

BMC Genomics 2007, 8:214 doi:10.1 186/147|-2164-8-214
Received: 31 January 2007

Accepted: 4 July 2007

This article is available from: http://www.biomedcentral.com/I47|-2|64/8/2I4

(c) 2007 Docherty et al; licensee BioMed Central Ltd.

This is an Open Access article distributed under the terms of the Creative Commons Attribution License (http://creativecommons.org/licenses/by/2.0), which permits unrestricted use, distribution, and reproduction in any medium, provided the original work is properly cited.

\begin{abstract}
Background: Genetic influences underpinning complex traits are thought to involve multiple quantitative trait loci (QTLs) of small effect size. Detection of such QTL associations requires systematic screening of large numbers of DNA markers within large sample populations. Using pooled DNA on SNP microarrays to screen for allelic frequency differences between groups such as cases and controls (called SNP Microarray and Pooling, or SNP-MaP) has been validated as an efficient solution on both $10 \mathrm{k}$ and $100 \mathrm{k}$ platforms. We demonstrate that this approach can be effectively applied to the truly genomewide Affymetrix GeneChip ${ }^{\circledR}$ Mapping $500 \mathrm{~K}$ Array.

Results: In comparisons between five independent DNA pools ( $N 200$ per pool) on separate Affymetrix GeneChip ${ }^{\circledR}$ Mapping $500 \mathrm{~K}$ Array sets, we show that, for SNPs with minor allele frequencies $>0.05$, the reliability of the rank order of estimated allele frequencies, assessed as the average correlation between allele frequency estimates across the DNA pools, was 0.948 (average mean difference across the five pools $=0.069$ ). Similarly, validity of the SNP-MaP approach was demonstrated by a rank-order correlation of 0.937 (average mean difference $=0.095$ ) between the average DNA pool allele frequency estimates and the allele frequencies of an independent (CEPH) sample of 60 unrelated individually genotyped subjects.

Conclusion: We conclude that SNP-MaP can be extended for use on the Affymetrix GeneChip ${ }^{\circledR}$ Mapping $500 \mathrm{~K}$ Array, providing a cost-effective, reliable and valid initial screen of $500 \mathrm{~K}$ SNP microarrays in genomewide association scans.
\end{abstract}

\section{Background}

The post-genomic era signals increased confidence in the possibility of locating quantitative trait loci (QTLs) that underpin the heritability of common complex disorders. However, problems still remain and progress towards reliably detecting QTLs for complex disorders, for which multiple genetic and environmental risk factors are responsible, has been slower than expected [1]. Hypothesis-driven candidate gene studies are important, but with approximately 25,000 genes in the human genome it is often difficult to predict how variation in gene product will affect a particular phenotype. Moreover, it may be a mistake to limit the search for QTLs to the $2 \%$ of the genome that codes for proteins, rather than using a 
genomewide strategy that considers non-coding as well as coding DNA sequences [2]. Linkage designs represent a genomewide approach but are limited to detecting QTLs of relatively large effect size $[3,4]$. Association designs are needed to provide genomewide searches for QTLs of small effect size but hundreds of thousands of DNA markers genotyped on samples of thousands of individuals are needed to detect QTLs of small effect size [5].

Microarrays that permit highly multiplexed genotyping greatly reduce this genotyping burden. Several companies have developed microarrays to meet the need for genomewide association analysis (most notably Affymetrix ${ }^{\mathrm{TM}}$ and Illumina $^{\mathrm{TM}}$ ). In each case, single nucleotide polymorphisms (SNPs) are the marker of choice because they are bi-allelic, abundant throughout the genome and relatively stable from generation to generation [6]. Alleles of SNPs close together on a chromosome will be correlated (that is, in linkage disequilibrium) and thus they are also likely to be associated with a QTL in between them, known as indirect association $[7,8]$.

The number of SNPs required for an indirect genomewide association study depends on several factors, including recombination frequencies, effect size, and sample size[9]. It is estimated however, that approximately 500,000 'randomly chosen' SNPs or approximately 250,000 well-chosen 'tag SNPs', which take into account patterns of linkage disequilibrium, are adequate to capture nearly all common variation in Caucasian, Han Chinese, and Japanese populations $[10,11]$.

With the advent of microarrays that genotype hundreds of thousands of SNPs, genomewide association studies are becoming a reality. For example, microarrays have been instrumental in genomewide association scans that discovered an intronic SNP in complement factor H (CFH) causing age related macular degeneration [12], and a non synonymous SNP in $I L 23 R$ - a gene encoding a subunit of a proinflammatory cytokine interleukin-23 receptor - that confers susceptibility to Crohn's disease [13]. However, these associations involve large effect sizes with odds ratios greater than 3.0; very large samples will be needed to detect smaller QTL effects.

The solution appears simple: Use microarrays to genotype large cohorts for hundreds of thousands of SNPs. However, despite the high throughput of SNP genotyping microarrays and the low cost per genotype, the cost of individually genotyping a sample of even 1000 individuals remains prohibitive outside of large-scale consortia. Until genotyping becomes even cheaper, one solution is to screen the genome using DNA pools on microarrays to nominate SNPs. DNA can be pooled for large samples of cases and controls or the low and high extremes of a quan- titative trait and the pooled DNA can be genotyped on

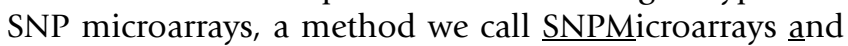
DNA Pooling (SNP-MaP). The technique of DNA pooling has been validated using both microsatellites [e.g., [1417]] and SNPs [e.g., [18-25]] on several genotyping platforms, including the Affymetrix $10 \mathrm{~K}$ microarray [26-32], $100 \mathrm{~K}$ microarray [33], and one half of the two-chip 500 $\mathrm{K}$ microarray set [34]. The main advantage of DNA pooling is that it provides average allele frequency estimates for a group rather than genotyping each individual in the group and then averaging their allele frequencies statistically. The main limitation is that individual genotypes and haplotypes cannot be extracted because the DNA of individuals is pooled.

The confirmation of previously identified associations with rheumatoid arthritis have demonstrated the feasibility of SNP-MaP case-control study designs for detecting susceptibility alleles to complex diseases [35]. Furthermore, substantive studies have already used pooled DNA across a variety of microarray platforms to detect novel SNP associations. SNP-MaP has been used as an initial screen in the identification of four susceptibility loci for mild mental impairment [36], 11 SNPs associated with reading ability [37], and several SNPs, including an intronic SNP from the diacylglycerol kinase eta (DGKH) gene, associated with bipolar disorder [38]. These studies were performed using Affymetrix $10 \mathrm{~K}$, Affymetrix $100 \mathrm{~K}$ and Illumina HumanHap550 microarrays, respectively. Moreover, the Affymetrix GeneChip ${ }^{\circledR}$ Mapping $500 \mathrm{~K}$ Array set has already been used to allelotype DNA pools in substantive research, implicating a KIBRA-encoding locus in memory performance [39].

In this report we evaluate the applicability of DNA pools on the first truly genomewide, commercially available genotyping platform, the Affymetrix $500 \mathrm{~K}$ GeneChip ${ }^{\varpi}$, which affords significantly greater coverage of all common variation than do $10 \mathrm{~K}$ and $100 \mathrm{~K}$ arrays [10]. Although already employed in substantive research, three subtle but potentially detrimental changes differentiating the Affymetrix $500 \mathrm{~K}$ GeneChip ${ }^{\circledR}$ from its validated $10 \mathrm{~K}$ and $100 \mathrm{~K}$ predecessors, deem validation of the full $500 \mathrm{~K}$ set with pooled DNA desirable. These changes are: 1) the introduction of two new restriction digest endonucleases, NspI and StyI; 2) a decrease in feature size from $8 \mu \mathrm{m}$ to 5 $\mu \mathrm{m}$; and 3) a reduction from 40 to 24 probes per SNP for $90 \%$ of the $500 \mathrm{~K}$ microarray.

To ascertain the reliability and validity of genomewide screening using DNA pools, we assayed five previously validated, independent DNA pools ( $N$ 200 independent individuals per pool) separately on Affymetrix GeneChip ${ }^{\text {}}$ Mapping $500 \mathrm{~K}$ Array sets. To assess reliability, the allele frequency estimates were compared across the five DNA 
pools. To assess validity, the average allele frequency estimates across the five pools were compared with a CEPH sample of 60 individuals from the HapMap project [11] previously genotyped using the Affymetrix $500 \mathrm{~K}$ GeneChip $^{\circledR}$.

\section{Results \\ Detection rates}

All five DNA pools produced similar detection rates with the $500 \mathrm{~K}$ GeneChip ${ }^{\circledR}$; rates varied from 87.9 to $97.5 \%$ for the Sty array and 92.3 to $97.9 \%$ for the Nsp array. These detection rates for the $500 \mathrm{~K}$ GeneChip $^{\circledR}$ were similar to those from our previous work using pooled DNA on the $10 \mathrm{~K}$ and $100 \mathrm{~K}$ GeneChip ${ }^{\circledR}$ platforms [29,32,33] and only slightly less than for individual genotyping of the reference DNA sample provided by Affymetrix (99.3\% for Sty, $98.9 \%$ for Nsp).

\section{Allele frequency estimation}

Rather than deriving separate RAS scores for sense and anti-sense quartets, allele frequencies can be estimated more reliably using a composite measure. Thus, allele frequency estimates were calculated using a modified form of the RAS score algorithm ( RAS $\left._{\mathrm{av}-\mathrm{all}}\right)$ based upon an average of all quartet measures.

\section{Reliability}

Reliability was assessed by correlating allele frequency estimates across the five DNA pools using the Pearson correlation coefficient $(r)$, as well as calculating their average absolute differences. As can be seen from Table 1, estimates of allele frequency across the $500 \mathrm{~K}$ microarray are highly reliable $(N=457,607-487,666$ SNPs for which $70 \%$ of quartet measurements were available). The average correlation among the five DNA pools was 0.956 and their average absolute difference was 0.066 .

It is possible that these estimates of reliability are inflated by the inclusion of low frequency alleles; particularly in the case of non-polymorphic alleles when all SNPs are considered. To control for this we re-ran these analyses using only SNPs with MAF > .05 $(N=428,179-456,241$ SNPs). Table 1 indicates similar results for correlations (0.948) and mean differences (0.069).

Because we employ multiple biological replicates (constructed singly) without technical replicates it is difficult to decompose variance attributable to microarray measurement and pooling construction. However, a recent paper using one microarray of the two-microarray Affymetrix $100 \mathrm{~K}$ set has estimated that the microarray component of variance is up to seven times greater than that of pool construction (variance due to microarray $\approx .00126$ $v s$. variance due to pool construction $\approx .00018$; [see [40]]). Given the relationship between $500 \mathrm{~K}$ and $100 \mathrm{~K}$ perform- ance (see below), we would expect to see similar estimates of microarray variance for the $500 \mathrm{~K}$ microarray.

\section{Validity}

To assess validity, we compared our estimates of allele frequencies from pooled DNA with individual genotyping data from an independent sample of $60 \mathrm{CEPH}$ individuals. All the CEPH individuals (as well as Han Chinese, Japanese and Yoruban populations) have been genotyped for SNPs on the Affymetrix $500 \mathrm{~K}$ microarray; these data, which have been acquired using multiple genotyping platforms, are available for download from the HapMap project [11]. Considering the small CEPH sample size, Table 2 indicates that the SNP-MaP approach exhibited reasonable validity, reflected by high correlations $(0.926$ on average for both arrays) and modest mean differences (0.100) between each pool and the CEPH population, with similar results for MAF > .05. We found no difference between array-type (Nspl or Styl) on indices of reliability or validity, regardless of whether all SNPs or just common SNPs (MAF > .05) were included.

As expected, validity was further improved when all five DNA sub-pool estimates were aggregated, supporting the use of multiple DNA sub-pools in SNP-MaP studies [33]. After excluding SNPs whose average minor allele frequency across the five pools was less than .05 or which had fewer than four pools, SNP-MaP estimates correlated 0.937 (mean difference $=0.095$ ) with the CEPH population ( $N=412,626$ SNPs). Standard errors of the mean (SEM) across at least four replicates were small (approximately $60 \%$ of the data exhibited SEMs $<0.025$ and $90 \%$ of the data exhibited SEMs < 0.045) but were predictive of validity, with smaller variance across replicates indicating greater accuracy. We estimate that with at least 4-5 biological replicate DNA pools, the SNP-MaP method has $80 \%$ power to detect allele frequency differences between case and controls on the order of .043 for rarer alleles $(.05<$ $\mathrm{MAF}<.10)$ and .095 for common alleles $(.45<\mathrm{MAF}<.5)$.

\section{Artificial pooling experiment as an indication of reliability} After the removal of rare alleles (MAF < .05), the average correlation between the allele frequencies of two simulated biological replicate DNA pools - each containing the individual genotypes of 30 unrelated individually genotyped CEPH individuals - was calculated as 0.959. This provides an expected correlation between two pools containing independent samples and no technical variance (microarray or pool construction). Although the difference between 0.959 and 0.948 (our observed estimates of reliability) is small, with a p-value of 0.01 it is significantly different, however; this significance should be interpreted with caution as this is likely to reflect the sheer immensity of SNPs correlated and does not act as a sum- 
Table I: Reliability of allele frequency estimates in DNA pools for SNPs on the Affymetrix $500 \mathrm{~K}$ microarray.

\begin{tabular}{|c|c|c|c|c|c|c|}
\hline \multirow[t]{2}{*}{ Array } & \multicolumn{3}{|c|}{ All SNPs } & \multicolumn{3}{|c|}{ MAF > .05 } \\
\hline & Worst & Best & Average & Worst & Best & Average \\
\hline Nspl (250 k) & $0.952(0.069)$ & $0.969(0.056)$ & $0.957(0.063)$ & $0.934(0.072)$ & $0.963(0.058)$ & $0.947(0.065)$ \\
\hline Styl (250 k) & $0.944(0.075)$ & $0.968(0.067)$ & $0.955(0.070)$ & $0.944(0.079)$ & $0.964(0.070)$ & $0.949(0.073)$ \\
\hline Both $(500 \mathrm{~K})$ & $0.949(0.07 I)$ & $0.962(0.062)$ & $0.956(0.066)$ & $0.94(0.075)$ & $0.956(0.065)$ & $0.948(0.069)$ \\
\hline
\end{tabular}

Values are mean Pearson correlation coefficients $(r)$ between the 5 DNA pools using the average of all quartet estimates (RAS av-all $)$. 'Worst' and 'Best' refer to the 10 bivariate comparisons between the 5 DNA pools and 'Average' is the average of these 10 correlations. Values in parentheses are mean absolute differences between DNA pools. 'All SNPs' includes all SNPs on the array (including rare and non-polymorphic SNPs) for which $70 \%$ of quartet measurements were available $(N=457,607-487,666$ across both microarrays). 'MAF $>.05$ ' only includes SNPs with minor allele frequency greater than $.05(N=428,179-456,241$ across both microarrays).

mary statistic that can be used to quantify case-control allele frequency differences across the microarray.

\section{Reliability and validity of the $500 \mathrm{~K}$ GeneChip ${ }^{\circledR}$ versus 100 $K$ GeneChip $^{\circledR}$}

Because the Affymetrix $500 \mathrm{~K}$ GeneChip ${ }^{\circledR}$ Mapping Array shares 27,281 probe-sets with the $100 \mathrm{~K}$ GeneChip ${ }^{\oplus}$, we investigated how similar the two platforms performed with the same DNA pools on the same SNPs. Overall, the $500 \mathrm{~K}$ platform performed slightly less well than the 100 $\mathrm{K}$ platform both in terms of reliability and validity. Using RAS $_{\text {av-all, }}$ indices of reliability (between DNA pool comparisons) for the $100 \mathrm{~K}$ microarray ranged from .958 to .977 (mean $=.967)$, whereas for the $500 \mathrm{~K}$ these correlations ranged from .933 to .949 (mean .940). This trend was mirrored in terms of validity when comparisons with the CEPH population were considered (data not shown).

\section{Discussion}

The ability to screen common SNPs for allele frequency differences with DNA pools is now feasible on a genomewide scale using the Affymetrix $500 \mathrm{~K}$ GeneChip ${ }^{\varpi}$ Mapping Array. We allelotyped five previously validated DNA pools on the $500 \mathrm{~K}$ microarray and show high reliability and validity for more than 500,000 SNPs.

It is important to note that estimates of reliability and validity, although high, were lower than those obtained using the $10 \mathrm{~K}$ [36] and $100 \mathrm{~K}$ [33] platforms . Comparing our previously published results for the $100 \mathrm{~K}$ platform versus the present results for the $500 \mathrm{~K}$ platform, the average reliability correlation was 0.969 for the $100 \mathrm{~K}$ vs. 0.948 for the $100 \mathrm{~K}$ (average absolute difference: 0.054 vs. 0.069 ); the average validity correlation was 0.939 vs. 0.916 (average absolute difference: 0.081 vs. 0.104 ). A reduction in both feature size and in the number of features per SNP may be accountable for this decline in performance from the $100 \mathrm{~K}$ array to the $500 \mathrm{~K}$ array. Nonetheless, the performance of the $500 \mathrm{~K}$ array is adequate, especially in comparison to the basic sampling variation seen in our artificial pools using the individually genotyped CEPH sample where no measurement error was present. Concerns may arise with Affymetrix's latest release, the SNP array 5.0, which sees all SNPs from the two-chip $500 \mathrm{~K}$ set, along with 420,000 additional nonpolymorphic probes which may be used to assess copy number variation, contained within a single microarray. As our analysis currently employs mis-match probe data, it remains to be seen if the reduction in the number of features per SNP required for such multiplexing will further reduce the reliability and validity of pooled DNA allele frequency estimates.

Thus, we conclude that allele frequency estimates from DNA pools appear reliable on the $500 \mathrm{~K}$ platform as well as $100 \mathrm{~K}$ and $10 \mathrm{~K}$ platforms to screen for allele frequency differences between groups. Despite the reliability and validity found for pooled DNA, three limitations of this

Table 2: Validity of allele frequency estimates in DNA pools for SNPs on the Affymetrix $500 \mathrm{~K}$ microarray.

\begin{tabular}{|c|c|c|c|c|c|c|}
\hline \multirow[t]{2}{*}{ Array } & \multicolumn{3}{|c|}{ All SNPs } & \multicolumn{3}{|c|}{ MAF > .05 } \\
\hline & Worst & Best & Average & Worst & Best & Average \\
\hline Nspl (250 k) & $0.913(0.108)$ & $0.942(0.089)$ & $0.928(0.099)$ & $0.902(0.113)$ & $0.935(0.093)$ & $0.918(0.103)$ \\
\hline Styl (250 k) & $0.903(0.114)$ & $0.943(0.089)$ & $0.925(0.101)$ & $0.889(0.119)$ & $0.936(0.093)$ & $0.914(0.106)$ \\
\hline Both (500 K) & $0.909(0.111)$ & $0.935(0.094)$ & $0.926(0.100)$ & $0.896(0.116)$ & $0.927(0.098)$ & $0.916(0.104)$ \\
\hline
\end{tabular}

Values are average Pearson correlation coefficients $(r)$ between the allele frequency estimates DNA pool and an independent population (CEPH) of 60 individuals. 'Worst' and 'Best' refer to the 10 bivariate comparisons between the 5 DNA pools and 'Average' is the average of these 10 correlations. Values in parentheses are mean absolute differences. 'All SNPs' includes all SNPs on the array including rare and non-polymorphic SNPs $(N=470,512-487,666)$. 'MAF > .05' only includes SNPs with minor allele frequency greater than $05(N=440,401-459,418)$. 
study should be mentioned, which put these results in an even more favourable light. Firstly, in terms of validity, these data are uncorrected for differential hybridisation kinetics, which can result in unequal representations of SNP alleles [27,31,33,41,42]. This is unimportant for individual genotyping as allele-calling algorithms routinely process - and, in the case of homozygotes, actually benefit from - discordant allele fluorescence values. If DNA pooling is used to estimate absolute allele frequencies, certain estimates will be biased when unequal allelic representation occurs. However, DNA pooling is rarely used to estimate absolute allelic frequencies. DNA pooling is usually used to assess relative differences between groups such as cases and control; previous reports of differential hybridisation [27] indicating that the proportion of SNPs exhibiting differential hybridisation (likely to result in type I and type II errors) is small, suggests all pools are subject to similar technical variation and thus allelic bias. A suitable next step however, is to identify the specific SNPs that exhibit large differential hybridisation and either omit these from subsequent analysis or correct in the appropriate manner [e.g., k correction; see [42,43]].

Secondly, the CEPH population that we used to determine validity is a relatively small sample, which will have undoubtedly reduced estimates of validity. Thirdly, reliability was assessed as the average difference between just one pool and another, rather than the difference between groups using multiple sub-pools for each group. It is therefore likely that our estimates of reliability are conservative underestimates, as may be inferred by the distribution of small SEMs.

DNA pooling involves several limitations. With DNA pooling it is not possible to extract individual genotypic information to allow analyses of individual differences or haplotypes. In addition, once individuals have been pooled they cannot be 'unpooled', thus tethering tests of allele frequency differences to the phenotype used for pooling [44]. However, these issues are offset by the considerable financial benefits of DNA pooling.

As with individual genotyping, issues of multiple testing and false positive results are critical for genomewide association analyses using SNP microarray. As one might expect, replication has been demonstrated to improve estimates of allele frequency, and therefore may be used to reduce, although by no means eliminate, the dilemma posed by false positive results [45]. Although no consensus has yet been reached as to the fairest method of analysing the enormous volume of data generated by genome-wide studies, especially for identifying QTLs of small effect size, progress with regard to high-throughput microarrays is being made [46]. Regardless of which statistical procedures are agreed upon that demonstrate ade- quate association, the ultimate criterion for association must be independent replication. The expense of individually genotyping large samples using SNP arrays makes replication of genomewide association scans unlikely. However, because DNA pooling is relatively inexpensive, SNP-MaP strategies will facilitate replication on a genomewide scale.

\section{Conclusion}

With results for reliability and validity similar to those previously demonstrated on $10 \mathrm{k}$ and $100 \mathrm{k}$ arrays, we have shown that the SNP-MaP approach can be applied to a $500 \mathrm{k}$ platform. We conclude that the Affymetrix $500 \mathrm{~K}$ GeneChip ${ }^{\circledast}$ Mapping Array can be used in SNP-MaP studies to provide an efficient, reliable, and valid genomewide screen of allele frequency differences between groups, thus facilitating the detection of SNPs of small effect size.

\section{Methods \\ Samples}

Five independent pools of DNA were created from a sample of 1028 white Caucasian individuals ( 538 females and 490 males) randomly selected from a representative community-based sample of more than 14,000 children in the Twins Early Development Study, which we used in a SNPMaP study of cognitive ability and disability with the $10 \mathrm{~K}$ microarray [36].

\section{DNA quantification and pool construction}

DNA samples were extracted from buccal swabs [47], quantified using a spectrophotometer $(260 \mathrm{~nm})$ and diluted to a target concentration of $50 \mathrm{ng} / \mu \mathrm{l}$. Each sample was subsequently quantified in triplicate using fluorimetry (employing PicoGreen ${ }^{\circledR}$ dsDNA quantitation reagent, Cambridge Bioscience, UK) and samples that were accurately quantified $( \pm 0.5 \mathrm{ng} / \mu \mathrm{l})$ were accepted for pooling. Each individual's DNA was randomly assigned to one of five DNA pools, thus providing five independent pools with 204-206 individuals. Each individual contributed $79.1 \mathrm{ng}$ of DNA to a DNA pool. Each pool concentration ranged from 13.33 to $13.57 \mathrm{ng} / \mu \mathrm{l}$.

\section{SNP microarray allelotyping of pooled DNA}

Because pooled DNA can be used only to estimate allelic frequency, not genotypic frequency, we refer to allelotyping rather than genotyping. Each of the five DNA pools was allelotyped using the GeneChip ${ }^{\circledast}$ Mapping $500 \mathrm{~K}$ Array set in accordance with the standard protocol for individual DNA samples (see the GeneChip ${ }^{\circledR}$ Mapping $500 \mathrm{~K}$ Assay Manual for full protocol). Each microarray was scanned using the GeneChip ${ }^{\circledR}$ Scanner 3000 with High-Resolution Scanning Upgrade, which was controlled using GeneChip ${ }^{\circledast}$ Operating software (GCOS) v1.4. Cell intensity (.cel) files were analyzed using GTYPE. Each of the five DNA pools was assayed on a separate microar- 
ray set; for quality control checks, a reference DNA individual provided by the manufacturer (sample number 100103) was also assayed on a separate microarray set.

\section{Generation of SNP-MaP allele frequency estimates}

Relative Allele Signal (RAS) scores, calculated using the 10 K MPAM Mapping algorithm, have been shown to be reliable and valid indices of allele frequency in pooled DNA [26-32]. Provided by Affymetrix, the GTYPE user's manual contains a full description of the Affymetrix Mapping GeneChip ${ }^{\circledast}$ probe-sets and how they are used to calculate RAS scores. Briefly, a RAS score for each SNP is derived from multiple 'quartet' measures. Quartets contain four 25 bp sequences (probes) with variations on the central base. The central base of the probe-set corresponds to two perfect match $(P M)$ probes and two mismatch $(M M)$ probes for each allele of the SNP, allele A $\left(P M_{A}\right.$ and $\left.M M_{A}\right)$ and allele $\mathrm{B}\left(P M_{\mathrm{B}}\right.$ and $\left.M M_{\mathrm{B}}\right)$. There is a 90:10 split between 6 and 10 quartet measures per SNP on the $500 \mathrm{~K}$ microarray set. These quartets occur either exclusively on the sense or anti-sense strand, or on both strands. The distribution of quartets relative to the SNP site varies from SNP to SNP but can include up to seven quartets up or downstream of the SNP site ('off-sets') including the SNP site itself ('zero offset') on a single strand. After subtracting the average mismatch intensity $(\overline{M M})$ from each $P M$ probe, a RAS score for each quartet is generated by calculating the ratio of $\mathrm{A}$ to $\mathrm{A}+\mathrm{B}$ fluorescence values. If $\overline{M M}>$ $P M_{A}$ OR $\overline{M M}>P M_{B^{\prime}} P M$ fluorescence values for that allele are set to 0 . In such instances ratios produce monomorphic RAS scores. If $\overline{M M}>P M_{\mathrm{A}}$ AND $\overline{M M}>P M_{\mathrm{B}}$, no interpretable signal is obtained (because the denominator is $0)$. In such instances the quartet was not used in subsequent analyses. Only SNPs that retained at least $70 \%$ of their available quartets were used in subsequent analyses (i.e., 5/6 or 7/10 quartets). Approximately $96 \%$ of SNPs are retained using this criterion, depending on the successfulness of the assay.

Allele frequency estimates for the $500 \mathrm{~K}$ microarray set were calculated manually from the raw probe intensity data exported as a .txt file, for reasons outlined previously [33]. In this study, however, we used a modified version of the RAS score algorithm that is based on an average of all quartet measures $\left(\mathrm{RAS}_{\mathrm{av}-\mathrm{all}}\right)$ rather than deriving separate RAS scores for sense and anti-sense quartets. The rationale for using RAS $_{\mathrm{av} \text {-all }}$ was twofold: Sense and antisense measures should not differ systematically and a composite measure should be more reliable.

\section{Analysis}

Reliability was assessed in relation to the average correlation between the 5 DNA pools across all SNPs. Validity was assessed by comparing average allele frequency estimates across 5 DNA pools to those from the independent sample available from HapMap [11] and NetAff ${ }^{\mathrm{TM}}$ [48]. The sample included 60 unrelated individuals from $\mathrm{CEPH}$ trios (30 mothers and 30 fathers) who were genotyped using the Affymetrix $500 \mathrm{~K}$ GeneChip ${ }^{\circledR}$ for the HapMap project [11].

\section{Artificially constructed pooling experiment}

To evaluate the level at which the observed SNP-MaP inter-chip reliability might compare to an ideal individual genotyping scenario, a simulated pooling experiment involving unrelated individuals was conducted using the genotypes of CEPH parents deposited in HapMap. Two independent pools were constructed: one comprising 30 CEPH mothers, the other $30 \mathrm{CEPH}$ fathers. The allele frequencies of the pools were calculated separately and then correlated with each other using SPSS.

\section{Authors' contributions}

SD wrote the manuscript and co-analysed the data. LB ran the microarrays, co-wrote the manuscript and co-analysed the data. LS co-wrote the manuscript and co-analysed the data. RP is principal investigator, conceived and designed the study and co-wrote the manuscript. All authors read and approved the final manuscript.

\section{Acknowledgements}

This work was supported in part by the U.K. Medical Research Council grant G0500079, Wellcome Trust grant GR75492, and grant HD4986I from the U.S. National Institute of Child Health and Human Development.

\section{References}

I. Collins FS, Green ED, Guttmacher AE, Guyer MS: A vision for the future of genomics research. Nature 2003, 422:835-847.

2. Mattick JS: RNA regulation: A new genetics? Nat Rev Genet 2004, 5:316-323.

3. Cardon LR, Bell J: Association study designs for complex diseases. Nat Genet 200I, 2:91-99.

4. Risch N, Merikangas KR: The future of genetic studies of complex human diseases. Science 1996, 273:1516-1517.

5. Hirschhorn JN, Daly MJ: Genome-wide association studies for common diseases and complex traits. Nat Rev Genet 2005, 6:95-108.

6. Brookes A]: The essence of SNPs. Gene 1999, 234:177-186.

7. Botstein $D$, Risch $N$ : Discovering genotypes underlying human phenotypes: past successes for Mendelian disease, future approaches for complex disease. Nat Genet 2003, 33:228-237.

8. Clayton D, Chapman J, Cooper J: Use of unphased multilocus genotype data in indirect association studies. Genet Epidemiol 2004, 27:415-428.

9. Xiong $M$, Guo SW: Fine-scale mapping based on linkage disequilibrium: theory and applications. Am J Hum Gen 1997, 60:1513-1531.

10. Barrett JC, Cardon LR: Evaluating coverage of genome-wide association studies. Nat Genet 2006, 38:659-662.

II. The International HapMap Consortium: The International HapMap Project. Nature 2003, 426:789-796. 
I2. Klein RJ, Zeiss C, Chew EY, Tsai JY, Sackler RS, Haynes C, et al.: Complement factor $\mathrm{H}$ polymorphism in age-related macular degeneration. Science 2005, 308:385-389.

13. Duerr RH, Taylor KD, Brant SR, Rioux JD, Silverberg MS, Daly MJ, et al.: A Genome-Wide Association Study Identifies IL23R as an Inflammatory Bowel Disease Gene. Science 2006, 3 | 4: |46|-|463.

14. Barcellos LF, Klitz W, Field LL, Tobias R, Bowcock AM, Wilson R, et al.: Association mapping of disease loci, by use of a pooled DNA genomic screen. Am J Hum Gen 1997, 6 I:734-747.

15. Daniels J, Holmans P, Plomin R, McGuffin P, Owen MJ: A simple method for analyzing microsatellite allele image patterns generated from DNA pools and its application to allelic association studies. Am J Hum Gen 1998, 62: I 189-1197.

16. Kirov G, Williams NM, Sham PC, Craddock N, Owen MJ: Pooled genotyping of microsatellite markers in parent-offspring trios. Genome Res 2000, 10:105-II5.

17. Pacek P, Sajantila A, Syvanen AC: Determination of allele frequencies at loci with length polymorphism by quantitative analysis of DNA amplified from pooled samples. $P C R$ Meth Appl 1993, 2:313-317.

18. Germer S, Higuchi R, Higuchi R: High-throughput SNP allele-frequency determination in pooled DNA samples by kinetic PCR. Genome Res 2000, 10:258-266.

19. Hoogendoorn B, Norton N, Kirov G, Williams N, Hamshere ML, Spurlock G, et al.: Cheap, accurate and rapid allele frequency estimation of single nucleotide polymorphisms by primer extension and DHPLC in DNA pools. Hum Genet 2000 1 07:488-493.

20. Norton N, Williams NM, Williams HJ, Spurlock G, Kirov G, Morris DW, et al: Universal, robust, highly quantitative SNP allele frequency measurement in DNA pools. Hum Genet 2002 I I 0:47 I-478.

21. Olsson C, Liljedahl U, Syvanen AC: Quantitative analysis of SNPs in pooled DNA samples by solid-phase minisequencing. Meth Mol Biol 2003, 21 2:167-176.

22. Ross P, Hall L, Haff LA: Quantitative approach to single-nucleotide polymorphism analysis using MALDI-TOF mass spectrometry. Biotechniques 2000, 29:620-6-628-9.

23. Sasaki T, Tahira T, Suzuki A, Higasa K, Kukita Y, Baba S, et al.: Precise estimation of allele frequencies of single-nucleotide poly morphisms by a quantitative SSCP analysis of pooled DNA. Am J Hum Gen 200I, 68:214-2I8.

24. Pearson JV, Huentelman MJ, Halperin RF, Tembe WD, Melquist S, Homer $\mathrm{N}$, et al: Identification of the genetic basis for complex disorders by use of pooling-based genomewide single-nucleotide-polymorphism association studies. Am J Hum Genet 2007, 80:126-139.

25. Bang-Ce Y, Peng Z, Bincheng Y, Songyang L: Estimation of relative allele frequencies of single-nucleotide polymorphisms in different populations by microarray hybridization of pooled DNA. Anal Biochem 2004, 333:72-78.

26. Brohede J, Dunne R, McKay JD, Hannan GN: PPC: an algorithm for accurate estimation of SNP allele frequencies in small equimolar pools of DNA using data from high density microarrays. Nucleic Acids Res 2006, 33:e I 42.

27. Simpson CL, Knight J, Butcher LM, Hansen VK, Meaburn E, Schalkwyk $L C$, et al: $A$ central resource for accurate allele frequency estimation from pooled DNA genotyped on DNA microarrays. Nucleic Acids Res 2005, 33:e25

28. Liu Q-R, Drgon T, Walther D, Johnson C, Poleskaya O, Hess J, et al: Pooled association genome scanning: Validation and use to identify addiction vulnerability loci in two samples. Proc Natl Acad Sci USA 2005, 102: I 1864- II 869.

29. Butcher LM, Meaburn E, Liu L, Fernandes C, Hill L, Al-Chalabi A, et al.: Genotyping pooled DNA on microarrays: A systematic genome screen of thousands of SNPs in large samples to detect QTLs for complex traits. Behav Genet 2004, 34:549-555.

30. Craig DW, Huentelman MJ, Hu-Lince D, Zismann VL, Kruer MC, Lee $A M$, et al.: Identification of disease causing loci using an arraybased genotyping approach on pooled DNA. BMC Genomics 2005, 6: 138

31. Kirov G, Nikolov I, Georgieva L, Moskvina V, Owen M, O'Donovan $M$ : Pooled DNA genotyping on Affymetrix SNP genotyping arrays. BMC Genomics 2006, 7:27.
32. Meaburn E, Butcher LM, Liu L, Fernandes C, Hansen V, Al-Chalabi A et al:: Genotyping DNA pools on microarrays: tackling the QTL problem of large samples and large numbers of SNPs. BMC Genomics 2005, 6:52

33. Meaburn E, Butcher LM, Plomin R, Schalkwyk L: Genotyping pooled DNA using 100 K SNP microarrays: a step towards genomewide association scans. Nucleic Acids Res 2006, 34:e27.

34. Wilkening S, Chen B, Wirtenberger M, Burwinkel B, Forsti A, Hemminki $\mathrm{K}$, et al:: Allelotyping of pooled DNA with $250 \mathrm{~K}$ SNP microarrays. BMC Genomics 2007, 8:77. 2007, Mar I6;

35. Steer S, Abkevich V, Gutin A, Cordell HJ, Gendall KL, Merriman ME, et al: Genomic DNA pooling for whole-genome association scans in complex disease: empirical demonstration of efficacy in rheumatoid arthritis. Genes Immun 2006, 8:57-68.

36. Butcher LM, Meaburn E, Knight J, Sham PC, Schalkwyk LC, Craig IW, et al:: SNPs, microarrays, and pooled DNA: identification of four loci associated with mild mental impairment in a sample of 6,000 children. Hum Mol Genet 2005, | 4: I 3 I 5-I325.

37. Meaburn E, Harlaar N, Craig IW, Schalkwyk LC, Plomin R: QTL association scan of early reading disability and ability using pooled DNA and I 00 K SNP microarrays in a sample of 5,500 children. Molecular Psychiatry in press.

38. Baum AE, Akula N, Cabanero M, Cardona I, Corona W, Klemens B, et al: A genome-wide association study implicates diacylglycerol kinase eta (DGKH) and several other genes in the etiology of bipolar disorder. Mol Psychiatry 2007.

39. Papassotiropoulos A, Stephan DA, Huentelman MJ, Hoerndli FJ, Craig DW, Pearson JV, et al.: Common Kibra Alleles Are Associated with Human Memory Performance. Science 2006, 3 I 4:475-478.

40. Macgregor S: Most pooling variation in array-based DNA pooling is attributable to array error rather than pool construction error. European Jounal of Human Genetics 2007, I 5:50 I-504.

4I. Brohede J, Dunne R, McKay JD, Hannan GN: PPC: an algorithm for accurate estimation of SNP allele frequencies in smal equimolar pools of DNA using data from high density microarrays. Nucleic Acids Res 2005, 33:e I 42.

42. Le Hellard S, Ballereau SJ, Visscher PM, Torrance HS, Pinson J, Morris SW, et al:: SNP genotyping on pooled DNAs: comparison of genotyping technologies and a semi automated method for data storage and analysis. Nucleic Acids Res 2002, 30:e74.

43. Moskvina V, Norton N, Williams N, Holmans P, Owen M, O'Donovan M: Streamlined analysis of pooled genotype data in SNP. based association studies. Genet Epidemiol 2005, 28:273-282.

44. Kruglyak L, Nickerson DA: Variation is the spice of life. Nat Genet 2001, 27:234-236.

45. Neale BM, Sham PC: The future of association studies: genebased analysis and replication. Am J Hum Gen 2004, 75:353-362.

46. Pe'er I, de Bakker PIW, Maller J, Yelensky R, Altshuler D, Daly M: Evaluating and improving power in whole-genome association studies using fixed marker sets. Nat Genet 2006 , 38:663-667.

47. Freeman B, Smith N, Curtis C, Huckett L, Mill J, Craig I: DNA from buccal swabs recruited by mail: evaluation of storage effects on long-term stability and suitability for multiplex polymerase chain reaction genotyping. Behav Genet 2003, 33:67-72.

48. Liu G, Loraine AE, Shigeta R, Cline M, Cheng J, Valmeekam V, et al: NetAffx: Affymetrix probesets and annotations. Nucleic Acids Res 2003, 3 I:82-86.

Publish with Biomed Central and every scientist can read your work free of charge

"BioMed Central will be the most significant development for disseminating the results of biomedical research in our lifetime. "

Sir Paul Nurse, Cancer Research UK

Your research papers will be:

- available free of charge to the entire biomedical community

- peer reviewed and published immediately upon acceptance

- cited in PubMed and archived on PubMed Centra

- yours - you keep the copyright 